\title{
The SBP2 protein central to selenoprotein synthesis contacts the human ribosome at expansion segment $7 \mathrm{~L}$ of the $28 \mathrm{~S}$ rRNA
}

\author{
OLGA KOSSINOVA, ${ }^{1,2}$ ALEXEY MALYGIN, ${ }^{1}$ ALAIN KROL, ${ }^{2,3}$ and GALINA KARPOVA ${ }^{1,3}$ \\ ${ }^{1}$ Institute of Chemical Biology and Fundamental Medicine, Siberian Branch of the Russian Academy of Sciences, Novosibirsk 630090, Russia \\ ${ }^{2}$ Architecture et Réactivité de l'ARN, Université de Strasbourg, CNRS, IBMC, 67084 Strasbourg, France
}

\begin{abstract}
SBP2 is a pivotal protein component in selenoprotein synthesis. It binds the SECIS stem-loop in the $3^{\prime}$ UTR of selenoprotein mRNA and interacts with both the specialized translation elongation factor and the ribosome at the 60S subunit. In this work, our goal was to identify the binding partners of SBP2 on the ribosome. Cross-linking experiments with bifunctional reagents demonstrated that the SBP2-binding site on the human ribosome is mainly formed by the $28 \mathrm{~S}$ rRA. Direct hydroxyl radical probing of the entire $28 \mathrm{~S}$ rRNA revealed that SBP2 bound to $80 \mathrm{~S}$ ribosomes or $60 \mathrm{~S}$ subunits protects helix ES7L-E in expansion segment 7 of the $28 \mathrm{~S}$ rRNA. Diepoxybutane cross-linking confirmed the interaction of SBP2 with helix ES7L-E. Additionally, binding of SBP2 to the ribosome led to increased reactivity toward chemical probes of a few bases in ES7L-E and in the universally conserved helix $\mathrm{H89}$, indicative of conformational changes in the $28 \mathrm{~S}$ rRNA in response to SBP2 binding. This study revealed for the first time that SBP2 makes direct contacts with a discrete region of the human $28 \mathrm{~S}$ rRNA.
\end{abstract}

Keywords: mammalian ribosome; cross-linking approach; chemical probing; selenocysteine incorporation; SECIS-binding protein 2

\section{INTRODUCTION}

Selenocysteine (Sec) insertion into a growing polypeptide chain occurs in response to a UGA codon redefined as Sec, otherwise acting as a stop codon. To enable UGA recoding to Sec in eukaryotes, several cis- and trans-acting factors are required. All eukaryotic selenoprotein mRNAs contain a stemloop in the $3^{\prime}$ UTR, called SECIS for SelenoCysteine Insertion Sequence (Berry et al. 1991). Key trans-acting factors are the translation elongation factor eEFSec that binds specifically the Sec-tRNA ${ }^{\text {Sec }}$ (Fagegaltier et al. 2000; Tujebajeva et al. 2000; Gonzalez-Flores et al. 2012), and the SECIS-binding protein 2 (SBP2) that interacts with the SECIS element (Copeland et al. 2000; Fletcher et al. 2001; Allmang et al. 2002). SBP2 occupies a central role in selenoprotein synthesis because it recruits the eEFSec $\cdot$ Sec-tRNA ${ }^{\mathrm{Sec}} \cdot \mathrm{GTP}$ complex (Fagegaltier et al. 2000; Tujebajeva et al. 2000; GonzalezFlores et al. 2012). SBP2 was functionally characterized in Drosophila, humans, and rat (Copeland et al. 2000; Lescure et al. 2002; Takeuchi et al. 2009). The mammalian SBP2 can be divided into two domains. The N-terminal domain has

\section{${ }^{3}$ Corresponding authors}

E-mail karpova@niboch.nsc.ru

E-mail a.krol@ibmc-cnrs.unistra.fr

Article published online ahead of print. Article and publication date are at http://www.rnajournal.org/cgi/doi/10.1261/rna.044917.114. an unknown function and is dispensable for selenoprotein synthesis in rabbit reticulocyte lysate (Copeland et al. 2000), while in this system the C-terminal part lacking the $344 \mathrm{~N}$-terminal amino acids (CTSBP2) is able to maintain efficient selenoprotein synthesis (Copeland et al. 2001).

SBP2-SECIS interactions have been studied in great detail. The SBP2 RNA-binding domain as well as the SBP2-binding site on the SECIS element have been investigated. The SBP2 RNA-binding domain is composed of two subdomains, the L7Ae RNA-binding domain (Copeland et al. 2001; Fletcher et al. 2001, Caban et al. 2007; Cléry et al. 2007) which is shared with a family of functionally unrelated proteins (Copeland et al. 2000; Allmang et al. 2002) and a conserved lysine-rich module called either the bipartite RNA-binding domain, the selenocysteine insertion domain (SID), or the K-rich (lysine-rich) region, according to investigators (Bubenik et al. 2007; Donovan et al. 2008; Takeuchi et al. 2009). Copeland et al. (2001) showed that SBP2 co-sediments with ribosomes extracted from cultured cells. We showed that SBP2 binds purified human ribosomes in vitro, and specifically the $60 \mathrm{~S}$

\footnotetext{
(c) 2014 Kossinova et al. This article is distributed exclusively by the RNA Society for the first 12 months after the full-issue publication date (see http://rnajournal.cshlp.org/site/misc/terms.xhtml). After 12 months, it is available under a Creative Commons License (Attribution-NonCommercial 4.0 International), as described at http://creativecommons.org/licenses/ by-nc/4.0/.
} 
but not the $40 \mathrm{~S}$ ribosomal subunit (Takeuchi et al. 2009). In that same study, we identified the amino acids that are crucial for the interaction with the 605 subunit, namely the KKPTSLKKIILKER $^{527-540}$ amino acids (Takeuchi et al. 2009). Also, we and others found that the IILKER residues are important for both SECIS and ribosome binding (Donovan et al. 2008; Takeuchi et al. 2009).

Further studies were carried out to deepen our knowledge on the mechanistic issues leading to selenoprotein synthesis. Upon binding of SBP2 to the 80 S ribosome, a few nucleotides in expansion segment ES31L and helix H89 of the 28S rRNA displayed increased accessibilities to a chemical reagent (Caban and Copeland 2012). These changes were proposed to be necessary for Sec-tRNA ${ }^{\text {Sec }}$ entry to the ribosome aminoacyl (A) site. Recently, with the use of a minimal selenoprotein mRNA, we showed that SBP2 is already associated with the SECIS at the $48 \mathrm{~S}$ initiation complex formation step; SBP2 stays bound to the ribosome after Sec-tRNA ${ }^{\mathrm{Sec}}$ accommodation to the A site and dissociates during transpeptidation (Kossinova et al. 2013). Nevertheless, despite this information, the location and structural organization of the SBP2binding site on the ribosome remained unknown.

In this work, we sought to identify the nature of the contacts that SBP2 establishes with the ribosome. To address this question in humans, we have applied several approaches in which the CTSBP2 recombinant protein was used. Using a cross-linking technique with bifunctional reagents, we showed that the ribosomal SBP2 binding site is mainly formed by the human $28 \mathrm{~S}$ ribosomal RNA. Chemical probing of the $28 \mathrm{~S}$ rRNA structure in complexes of CTSBP2 with the human $80 \mathrm{~S}$ ribosomes or $60 \mathrm{~S}$ subunits led us to determine the $28 \mathrm{~S}$ rRNA regions changing accessibility to the probes upon CTSBP2 binding. Hydroxyl radical footprinting revealed that in both $80 \mathrm{~S}$ and $60 \mathrm{~S}$ ribosomes CTSBP2 protects a discrete region in helix ES7L-E in expansion segment ES7L of the $28 \mathrm{~S}$ rRNA. Diepoxybutane cross-linking proved that the ribosome-bound CTSBP2 indeed interacts with ES7L-E. We showed that the ES7L-E 2D structure is exquisitely conserved in vertebrates and a few invertebrates. Additionally, a few bases in helices H89 and ES7L-E displayed increased reactivity toward dimethylsulfate upon CTSBP2 binding. Altogether, when mapped on the cryo-EM structure model of the human 80 S ribosome (Anger et al. 2013) our data suggest that the SBP2-binding site is located on the solvent side of the 60S subunit, close to the ribosomal A site. Our results reported herein provide for the first time the evidence that $\mathrm{SBP} 2$ contacts a discrete region of the $28 \mathrm{~S}$ rRNA.

\section{RESULTS}

\section{SBP2 contacts the $28 \mathrm{~S}$ ribosomal rRNA in the $60 \mathrm{~S}$ ribosomal subunit}

In a previous work (Takeuchi et al. 2009) we showed that CTSBP2 binds exclusively the $60 \mathrm{~S}$ but not to $40 \mathrm{~S}$ ribosomal subunit. However, as the actual localization of the CTSBP2binding site on the ribosome was not identified at the time, we set out to determine it. At the onset, we established conditions for optimal formation of the SBP2 •ribosome complex. The human recombinant CTSBP2 protein used in this and further experiments contained amino acids $345-856$ and, as shown earlier, it is active in selenoprotein synthesis in rabbit reticulocyte lysate (Copeland et al. 2000; Lescure et al. 2002; Takeuchi et al. 2009). We determined that the binding of CTSBP2 to the purified human $60 \mathrm{~S}$ ribosomal subunits is almost stoichiometric at a threefold excess of CTSBP2 over purified human ribosomes used at $0.5 \mu \mathrm{M}$ (Fig. 1, lane 2). These conditions were used in all of the experiments described below.

To identify the ribosomal components interacting with SBP2, 80S·CTSBP2, 60S•CTSBP2 (and 40S•CTSBP2 as the control) complexes were treated with two bifunctional reagents, diepoxybutane or 2-iminothiolane. Diepoxybutane is highly reactive toward $-\mathrm{NH}_{2}$ and $-\mathrm{SH}$ groups of proteins and $\mathrm{G}, \mathrm{C}$, and A residues in RNAs, forming near $4 \AA$-length RNA-protein and protein-protein cross-links (Baumert et al. 1978; Koskinen and Plna 2000); 2-iminothiolane can act either as an RNA-protein (cross-linking radius $5 \AA$ ) or a protein-protein cross-linker (cross-linking radius $14 \AA$ ), depending on the reaction conditions used to generate the cross-link; it reacts with the $-\mathrm{NH}_{2}$ groups of lysines and $\mathrm{U}$ residues in RNAs (Traut et al. 1973). After treatment of the complexes with the bifunctional reagents, the distribution of cross-linked CTSBP2 between subunits as well as between ribosomal proteins and rRNAs was analyzed by dot-blotting with anti-SBP2 antibodies (Fig. 2). With diepoxybutane, we found that CTSBP2 cross-links only to the 605 and not the $40 \mathrm{~S}$ subunit in the $80 \mathrm{~S}$ ribosome (Fig. $2 \mathrm{~A}$ ). Furthermore, analysis of the cross-link distribution in the 60S CTSBP2 complex revealed that the SBP2 signal was $\sim 10$-fold higher in the rRNA than in the ribosomal protein fraction, both with diepoxybutane and 2-iminothiolane (Fig. 2B). This strongly suggests that the rRNA contributes mainly to the formation of the SBP2-binding site. We cannot rule out, though, that the lower

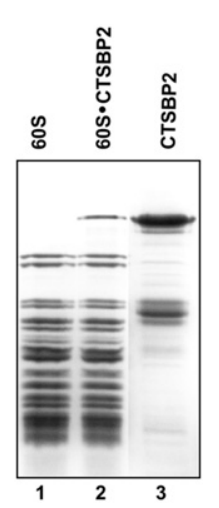

FIGURE 1. SBP2 binding to 605 ribosomal subunits. The CTSBP2 $\bullet 60$ S complex was isolated by sucrose gradient centrifugation and further loaded on SDS-PAGE (lane 2). Free 60S subunits (lane 1) and recombinant CTSBP2 (lane 3) were used as markers. The gel was Coomassie stained. 


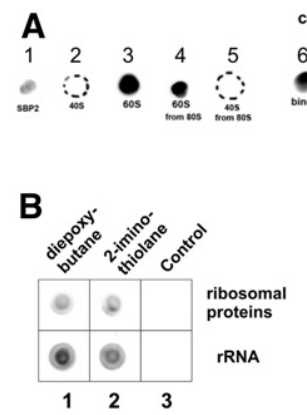

C

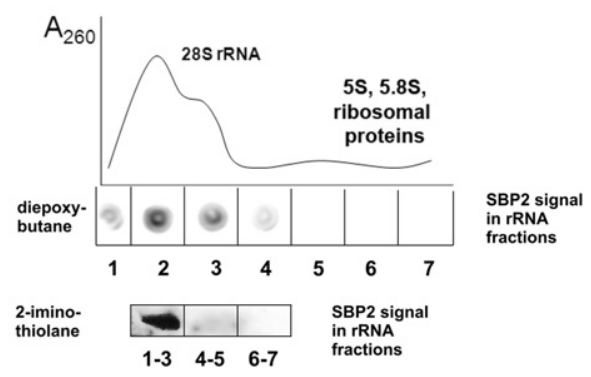

FIGURE 2. CTSBP2-ribosome cross-linking using bifunctional reagents. (A) Distribution analysis of the diepoxybutane-induced SBP2-ribosome cross-links among ribosomal subunits isolated by sucrose gradient centrifugation under dissociation conditions. (1) CTSBP2 alone as the control; (2) 40S•CTSBP2 complex; (3) 60S•CTSBP2 complex; $(4,5) 60 \mathrm{~S}$ and $40 \mathrm{~S}$ subunits, respectively, isolated from the 80 S ${ }^{\circ}$ CTSBP 2 complex; (6) 60S•CTSBP2 complex purified by sucrose gradient under nondissociating conditions; (7) 60S•CTSBP2 complex untreated with diepoxybutane but purified by sucrose gradient under dissociation conditions. (B) Dot blot analysis of the SBP2ribosome cross-link distribution among ribosomal proteins and rRNA; treatment with diepoxybutane (lane 1), 2-iminothiolane (lane 2), Control (lane 3): SBP2•ribosome complexes untreated with the bifunctional reagents. $(C)$ Dot-blot analysis of diepoxybutane- (top) or 2-iminothiolane(bottom) induced CTSBP2-rRNA cross-links. After chemical treatment, rRNAs were isolated from the 60 - CTSBP 2 complexes by SDS-EDTA sucrose gradient; a sucrose gradient sedimentation profile is shown. Gradient fractions are indicated below the dot blots. CTSBP2 signals were obtained by dot blot analysis with anti-SBP2 antibodies.

yield of CTSBP2 cross-links to ribosomal proteins originates from a smaller number of appropriate cross-linking targets in proteins surrounding CTSBP2. To examine which of the three $28 \mathrm{~S}$, 5S, or 5.8S rRNAs cross-linked to CTSBP2 in the $60 S \cdot C T S B P 2$ complex, the complex was treated either with 2-iminothiolane under conditions where only RNA-protein cross-links are formed or with diepoxybutane. Following isolation of the cross-linked rRNA and proteins by SDS-EDTA sucrose gradient ultracentrifugation, the immunoblotting analysis revealed that only the $28 \mathrm{~S}$ rRNA cross-linked to CTSBP2; no cross-link could be observed with the $5 \mathrm{~S}$ or 5.8S rRNAs (Fig. 2C). To evaluate how many ribosomal proteins cross-linked to CTSBP2, the 60S ribosomal protein-containing fraction was analyzed by 1D SDS-PAGE with subsequent immunoblotting using anti-SBP2 antibody. However, cross-links of SBP2 to ribosomal proteins were detected with neither diepoxybutane nor with 2-iminothiolane (data not shown). Therefore, the signals observed in the ribosomal protein fractions in Figure $2 \mathrm{~B}$ are likely due to their contamination with short $28 \mathrm{~S}$ rRNA fragments cross-linked to CTSBP2, maybe arising from partial rRNA degradation, and not precipitated by acetic acid. Thus, we can conclude that the SBP2-binding site on the 80S ribosome is located on its large subunit only and formed mainly by the $28 \mathrm{~S}$ rRNA.

\section{Hydroxyl radical probing of the $28 \mathrm{~S}$ rRNA shows protection of discrete regions in expansion segment ES7L-E in SBP2-bound 80 S and 60S human ribosomes}

We next sought to determine the regions of the $28 \mathrm{~S}$ rRNA that are protected by SBP2 in the ribosome. To do so, hydroxyl radical probing of the $28 \mathrm{~S}$ rRNA was carried out with the
80S•CTSBP2 and 60S•CTSBP2 complexes. Hydroxyl radicals attack the $\mathrm{C}^{\prime}$ atom of exposed ribose residues and thus induce strand scissions in the rRNA phosphodiester bonds (Wu et al. 1983). Positions of the scissions were detected by primer extension of $5^{\prime 32} \mathrm{P}$-labeled oligodeoxyribonucleotides. Almost all of the about 5000 nucleotides of the human 28S rRNA sequence were analyzed, with the exception of three regions: 50 nucleotides and 80 nucleotides at the very $5^{\prime}$ and $3^{\prime}$ ends, respectively, and 230 nucleotides in expansion segment ES27L; this was due to the presence of highly GC-rich regions impeding primer hybridization. The location of the 28S rRNA regions protected by CTSBP2 against hydroxyl attack was mapped on the 28S rRNA 2D structure model derived from the cryoEM structure of the human ribosome (Anger et al. 2013). The footprints reside in two regions of expansion segment ES7L whose accessibilities to hydroxyl radical attack were altered in the 60S•CTSBP2 complex vs. the free 60S subunits: Both regions were highly accessible in the free 60S subunits but displayed decreased accessibilities in the presence of CTSBP2 (Fig. 3A, cf. lane 2 with 3 and lane 9 with 10). These regions are 1133-1141, 1173-1186, and 1189-1190 at the apex of helices ES7L-F and ES7L-E, respectively (Fig. 3C). Using the SHAPE strategy, which leads to acylation of accessible $2^{\prime} \mathrm{OH}$ ribose residues, Caban and Copeland (2012) reported that SBP2 binding to the ribosome altered the reactivity of certain residues encompassing positions C4421 and U4419 in helix H89 and 4080-4166 in ES31L (numbering according to Anger et al. 2013). However, our footprinting experiments showed no differences in the accessibilities to hydroxyl radicals of these regions in the 60S•CTSBP2 complex (Supplemental Fig. S1), implying that at least the $\mathrm{C}^{\prime}$ atoms of riboses (which are sensed by $\mathrm{OH}$ radicals) in those regions of H89 and ES31L are not involved in the CTSBP2-induced conformational changes. The same hydroxyl radical treatment was performed with the $80 \mathrm{~S} \cdot \mathrm{CTSBP} 2$ complex to ask whether association of the $40 \mathrm{~S}$ subunit could change the pattern of SBP2 protection on the $28 \mathrm{~S}$ rRNA. To establish specificity of the SBP2 interactions with the ribosome, the same treatment was carried out with the $80 \mathrm{~S}$ in the presence of the SBP2 mutant (MutSBP2) containing AAA ${ }^{529-531}$ instead of TSL ${ }^{529-531}$ and which is unable to bind the ribosome (Takeuchi et al. 2009). Supplemental Figure S2A (lane 8) showed that MutSBP2 was unable to generate a footprint, indicating that the footprints observed with ES7L-E were indeed due to the specific SBP2-ribosome interaction. Positions 1133-1141 in ES7L-F were not protected in the 80S ribosomal complex (Supplemental Fig. S2B); lack of protections in this 

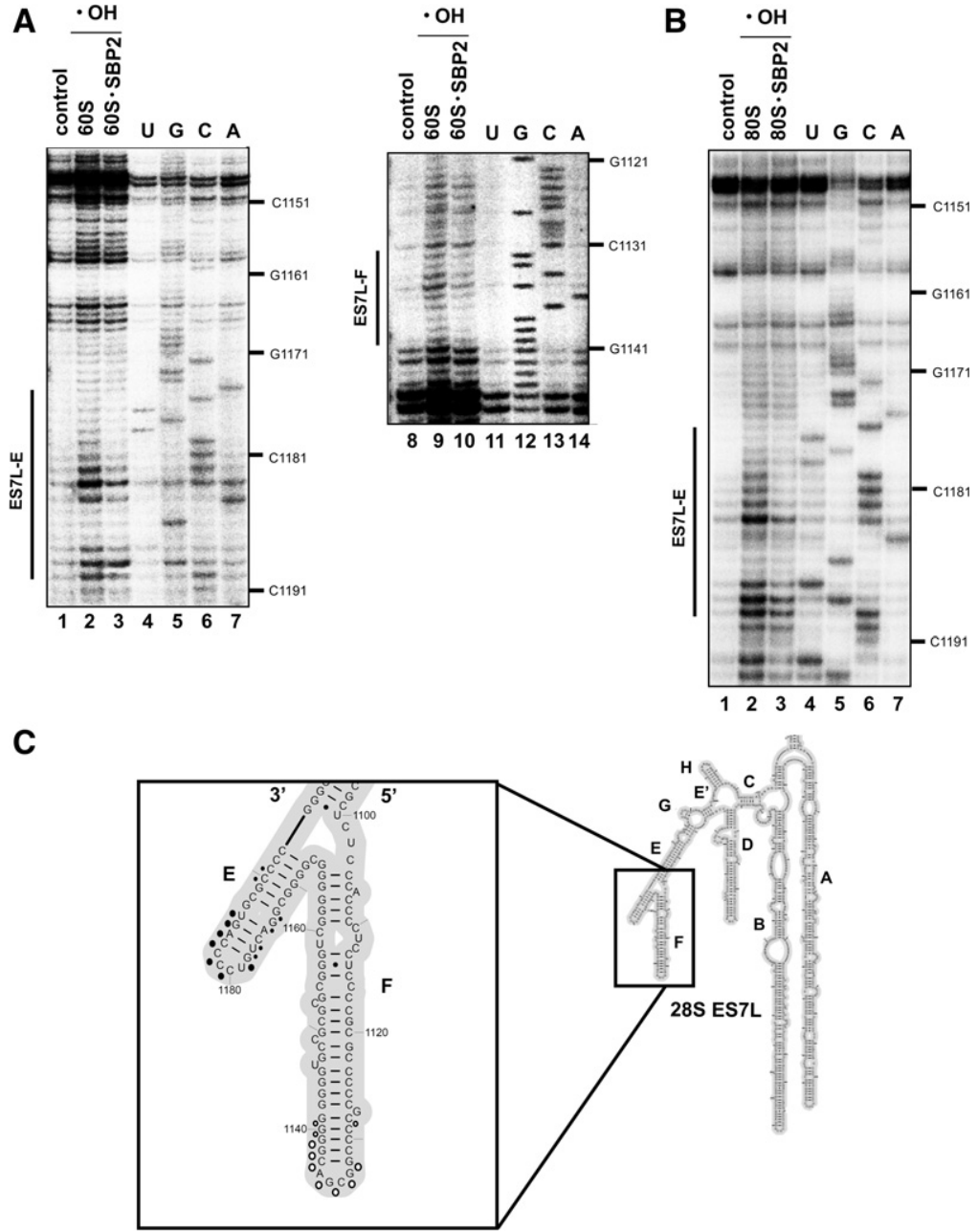

FIGURE 3. Direct hydroxyl radical probing of the human $28 \mathrm{~S}$ rRNA in $605 \cdot \mathrm{CTSBP} 2(A)$ and 80 S CTSBP2 $(B)$ complexes. The sites of the hydroxyl radical-induced cleavages were mapped on the $28 \mathrm{~S}$ rRNA by reverse transcription; reverse transcriptase stopped $3^{\prime}$ to the nucleotides whose ribose moieties were subjected to hydroxyl radical attack. Lanes 2,3,9,10 contained hydroxyl radicals ( $\left.{ }^{\circ} \mathrm{OH}\right)$. Lanes 1,8 lack hydroxyl radicals; lanes 2 and 9 lack CTSBP2. The extent of protection by CTSBP2 is shown on the left by a vertical bar indicating also the name of the protected helix. $(C)$ The sites of protection identified in $A$ and $B$ are mapped onto the secondary structure of the 28S rRNA expansion segment ES7L (Anger et al. 2013); a blow-up of helices E and F of ES7L is displayed in the inset. Protections observed in both the 60S•CTSBP 2 and $80 S \cdot \mathrm{CTSBP} 2$ complexes are shown as closed circles, those found only in the 60S•CTSBP2 complex as open circles. Larger circles indicate higher protection. U,G,C,A lanes are sequencing markers.

region is likely due to structural rearrangements following subunit association. Again, as with the 60S•CTSBP2 complex, no change in the protection pattern was detected either in $\mathrm{H} 89$ or ES31L (Supplemental Fig. S2C,D).

\section{Diepoxybutane cross-linking validates the CTSBP2-ES7L-E interaction}

To validate the hydroxyl radical probing data, we asked whether ES7L-E is in close proximity to CTSBP2 in the 80S•CTSBP2 complex. Besides, as H89 was found to adopt a conformation change upon CTSBP2 binding (Caban and
Copeland 2012), we sought to determine whether CTSBP2 contacts H89. To answer these questions, we analyzed by reverse transcription the $28 \mathrm{~S}$ rRNA isolated from $80 \mathrm{~S}$ ribosomes treated by diepoxybutane in the presence of either wild-type CTSBP2 or the SBP2 mutant MutSBP2. Nucleotides C1183, G1189, G1194, and G1195 were cross-linked to CTSBP2 (Fig. 4, cf. lanes 6 and 7). These positions overlap the area found to be protected against hydroxyl radical attack. The lack of reverse transcription stops with MutSBP2 at these positions argues for the specificity of the cross-links (Fig. 4, cf. lanes 7 and 8). Taking into account that diepoxybutane forms near $4 \AA$-length RNA-protein cross-links, one can conclude that the four identified nucleotides tightly surround CTSBP2 on the ribosome or even contact it. Remarkably, no nucleotide was found to cross-link in the H89 region (which displayed increased accessibility toward benzoyl cyanide in the 80S•CTSBP2 complex) (Caban and Copeland 2012), and in the ES7L-F region protected by CTSBP2 from hydroxyl radical attack in the 60S- CTSBP2 complex (Supplemental Fig. S3A,B).

\section{Chemical probing of helices ES7L-E and $\mathrm{H} 89$ reveals conformation changes upon SBP2 binding to the human 605 subunit}

The protections against hydroxyl radical attack observed at the sugar-phosphate backbone of helix ES7L-E led us to ask whether changes in the accessibility of the chemical groups of the bases could also be observed in this helix upon SBP2 binding to the $60 \mathrm{~S}$ subunit. To this end, we performed chemical probing of the $28 \mathrm{~S}$ rRNA in the $605 \cdot \mathrm{CTSBP} 2$ complex with kethoxal or dimethylsulfate (DMS). Kethoxal treatment creates a cyclic adduct between the $\mathrm{N} 1$ and $\mathrm{N} 2$ positions of unpaired guanines, DMS methylates N1 of adenines, and N3 of cytosines when they are unpaired as well. Modified positions were identified by the primer extension method. Figure 5A shows the result of the DMS and kethoxal treatments at ES7L-E. Three positions were modified by DMS, C1180, C1181, and C1182. C1182 is highly modified in the free and complexed subunit; however, only C1180 and C1181 displayed an increased reactivity in the $60 \mathrm{~S} \cdot \mathrm{CTSBP} 2$ complex vs. the free subunit (Fig. 5A, cf. lanes 6 and 7). G1185 reactivity toward 


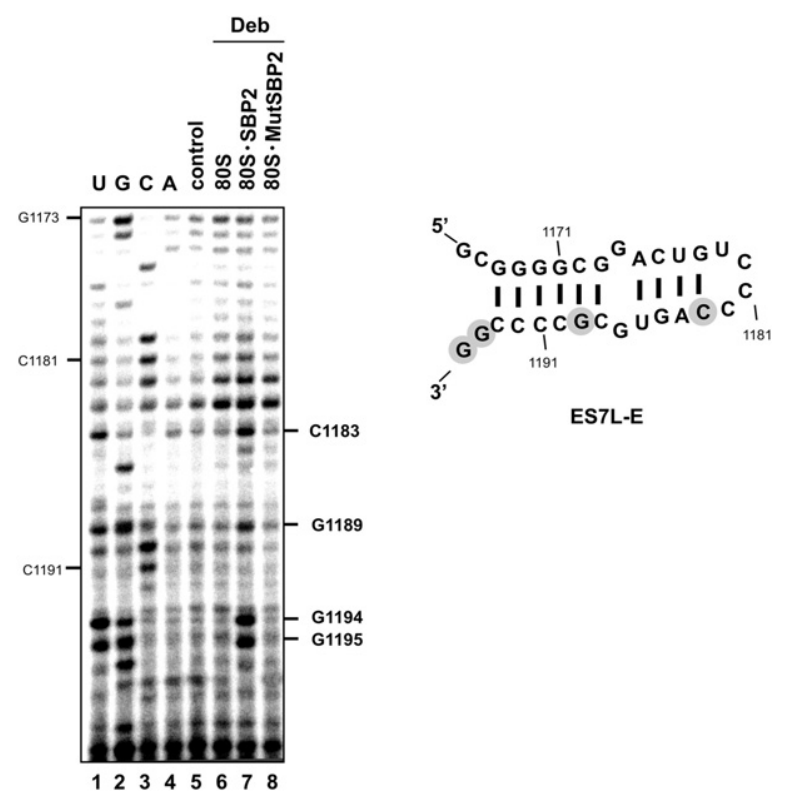

FIGURE 4. CTSBP2-ES7L-E cross-linking with diepoxybutane. Modified nucleotides are marked on the right of the gels. The modification site is one nucleotide prior to the stop (e.g., the stop observed at A1184 means that C1183 was modified); when the reverse transcription stop was observed at a $\mathrm{G}$, this position was considered as modified because diepoxybutane reacts with the N7G atom which is not involved in Watson-Crick base-pairing: Reverse transcriptase only pauses. (Lane 7) Wild-type CTSBP2. Lane 8 contained the SBP2 mutant version MutSBP2. Lanes 6,7,8 contained diepoxybutane (Deb). Lane 5 lacked Deb. U,G,C,A lanes are sequencing markers. Cross-linked nucleotides (shown in gray circles) were mapped onto the secondary structure of ES7L-E (Anger et al. 2013).

kethoxal is increased in the 60S $\cdot \mathrm{CTSBP} 2$ complex compared with the free subunit (Fig. 5A, cf. lanes 13 and 14). As for ES7L-F, it displayed the same reactivity toward DMS and kethoxal in both the free 60S subunits and 60S.CTSBP2 complexes (Supplemental Fig. S4A).

As mentioned above, no protection against or increased reactivity toward hydroxyl radical attack was detected in ES31L or helix H89 upon binding of CTSBP2. As hydroxyl radicals attack the $\mathrm{C} 4{ }^{\prime}$ ribose, our findings do not rule out the possibility that chemical groups of bases in H89 and ES31 have their accessibility altered upon SBP2 binding. Chemical probing was therefore performed to examine this hypothesis. ES31L displayed the same reactivity toward kethoxal and DMS in both the free 60S subunits and 60S.CTSBP2 complexes, implying that the bases in this region are not involved in the CTSBP2-induced conformational changes of the $28 \mathrm{~S}$ rRNA observed in Caban and Copeland (2012) (Supplemental Fig. S4B). In H89, A4414, A4415, A4422, A4424, and A4428 were modified by DMS (Fig. 5B). Among these, reactivities of A4414 and A4422 were higher in the 60S ${ }^{\cdot}$ CTSBP2 complex than in the free 605 subunit (Fig. 5B, cf. lanes 6 and 7), as a direct or indirect consequence of SBP2 binding to the ribosome. No significant increase of kethoxal modification was observed upon SBP2 binding (Fig. 5B, lanes 9,10).

\section{Structure-based sequence alignment reveals the extreme evolutionary conservation of a part of helix ES7L-E 2D structure}

The footprints that were observed in ES7L-E in the presence of CTSBP2 raised the question of whether the 2D structure of this helix is conserved in selenoprotein-making organisms to enable SBP2 to bind. To answer this question, we analyzed the sequences of several $28 \mathrm{~S}$ rRNAs between positions 956 and 1284 encompassing helices ES7L-E and ES7L-F (numbering according to the human $28 \mathrm{~S}$ rRNA sequence from Anger et al. [2013]). Sequences that could not be manually folded as ES7L-E because of high-sequence dissimilarities and/or the presence of blocks of extended deletions, were discarded. For example, the sequences of Anopheles gambiae (Cannone et al. 2002), Plasmodium falciparum (Cannone et al. 2002), Drosophila melanogaster (Anger et al. 2013), and Tetrahymena thermophila (Klinge et al. 2011) could not be considered because they possess much shorter ES7L sequences. Twelve organisms (10 vertebrates, one echinoderm, and one mollusk) were submitted to LocARNA (Will et al. 2007), a web-based tool, which simultaneously folds the input sequences and aligns them. Figure 6, A and B, reveals the perfect evolutionary conservation of the $2 \mathrm{D}$ structure of helix ES7L-E between positions 1170 and 1191 owing to a number of base covariations. The sequence of the G1171C1190 and C1176-G1185 base pairs (human numbering) is conserved in the 12 organisms. Such a 2D structure conservation is indicative of a functional role of this helix.

\section{Correlation between the sequence of the SBP2 K-rich region and the structure of the human $28 \mathrm{~S}$ rRNA ES7L-E expansion segment}

In an earlier work, we showed that the KKPTSLKKIILK $\mathrm{ER}^{527-540}$ motif of the $\mathrm{K}$ (lysine)-rich domain in the human SBP2 is crucial for binding to the 60S ribosomal subunit (Takeuchi et al. 2009); these amino acids are conserved in the majority of the SBP2 sequenced so far, from sea urchin to mammals; however, insect SBP2 possesses the KK ITRLKKSVRVY instead of the KKPTSLKKIILKER sequence, and the sequence difference in the C-terminal part of this motif (SVRVY instead of IILKER) is by itself sufficient to change the pattern of SECIS recognition (Takeuchi et al. 2009). Interestingly, the length of the $D$. melanogaster $28 \mathrm{~S}$ RNA ES7L is shorter and its sequence and 2D structure differ from the human counterpart due to deletions/point mutations (Anger et al. 2013). This led us to ask whether a correlation exists between the type of ES7L sequence/2D structure and the amino acid sequence in the SBP2 K-rich domain. To this end, we performed a multiple alignment of SBP2 amino acid sequences that are annotated in databases and 

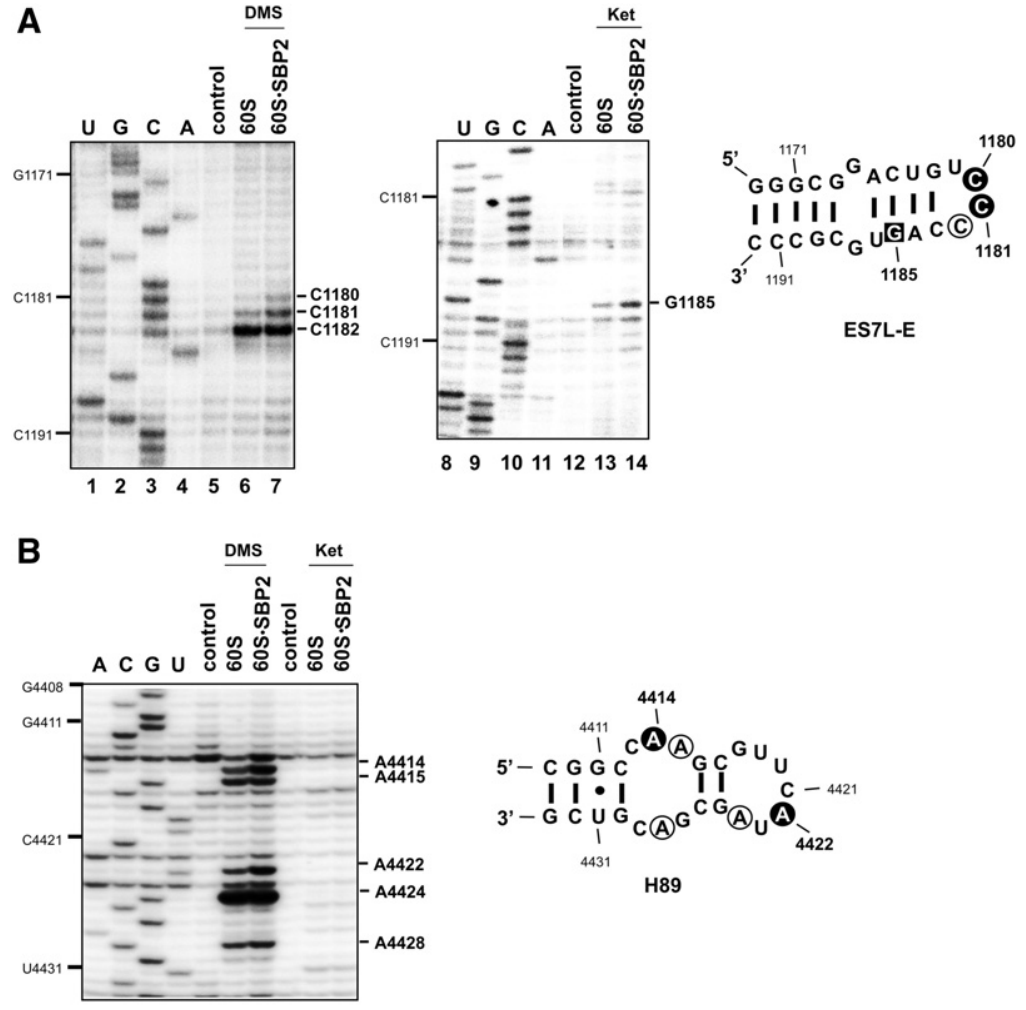

$\begin{array}{lllllllllll}1 & 2 & 3 & 4 & 5 & 6 & 7 & 8 & 9 & 10\end{array}$

FIGURE 5. Chemical probing of the $28 \mathrm{~S}$ rRNA in $60 \mathrm{~S} \cdot \mathrm{CTSBP} 2$ complexes. Reverse transcription analysis of the $28 \mathrm{~S}$ rRNA in the ES7L-E and $\mathrm{H} 89$ regions is displayed in $A$ and $B$, respectively. Modified nucleotides (one nucleotide prior to the reverse transcriptase stops) are marked on the right of the gels. Reactions contained DMS $(A, B$, lanes 6,7) or kethoxal (Ket: $A$, lanes 13,14; $B$, lanes 9,10). Control lanes 5,12 $(A)$ and 5,8 $(B)$ did not contain DMS or kethoxal; CTSBP2 was not added in lanes 6,13 $(A)$ and 6,9 $(B)$. Modified positions are mapped onto the secondary structures of ES7L-E and H89 (Anger et al. 2013). Bases modified by DMS are in open circles, bases displaying increased reactivity toward DMS are displayed in a dark background; G1185 (boxed in ES7L-E) has an increased accessibility toward kethoxal modification. U,G,C,A lanes are sequencing markers. A gel compression led to stacking of the CG sequence at positions 1188-1189; resolution is better with the kethoxal gel.

originating from two protozoa, three insects, and five vertebrate selenoprotein-synthesizing organisms (other vertebrate sequences are available but did not bring new information because of the high-sequence conservation between vertebrate species). Figure 7 shows that the finding observed in Drosophila (see above) extends to other species, while the KKPTSLKKIILKER sequence occurs only in vertebrates. In addition, an insertion of variable length is found in protozoan SBP2.

ES7L segments differ dramatically in length and nucleotide sequence between protozoa and insects as well as with vertebrates (Cannone et al. 2002). As mentioned above, these organisms have no helix homologous to ES7L-E; the lack of obvious sequence conservation, and the presence of deletions in these organisms did not enable us to propose a $2 \mathrm{D}$ structure model similar or homologous to helix ES7L-E.

In conclusion, our sequence analysis revealed the existence of a correlation between the concomitant presence or absence of the KKPTSLKKIILKER sequence in the K-rich region of
SBP2 and the existence (or the lack) of the ES7L-E helix in 28S (26S) rRNAs.

\section{DISCUSSION}

The SBP2 protein plays a pivotal role in selenoprotein synthesis. It binds the SECIS element in the $3^{\prime}$ UTR of selenoprotein mRNAs and the translation elongation factor eEFSec to carry the eEFSec-Sec-tRNA ${ }^{\mathrm{Sec}} \cdot$ GTP ternary complex to the ribosomal A site (Copeland et al. 2000; Tujebajeva et al. 2000; Gonzalez-Flores et al. 2012). Our previous work established that SBP2 binds to the $60 \mathrm{~S}$ ribosomal subunit (Takeuchi et al. 2009) and we and others identified the SBP2 amino acids responsible for the interaction (Caban et al. 2007; Donovan et al. 2008; Takeuchi et al. 2009). However, the important question of the localization of the SBP2-binding site on the ribosome had not been solved. We addressed it in this work by using various approaches utilizing cross-linking and diverse chemical probes. We have found by hydroxyl radical footprinting experiments that the $80 \mathrm{~S}$ ribosome-bound SBP2 protects a discrete region of the sugar-phosphate backbone of the $28 \mathrm{~S}$ rRNA, namely, nucleotides 1173-1186 and 1189-1190 in helix ES7L-E. Diepoxybutane cross-linking validated the hydroxyl radical probing data and highlighted nucleotides C1183, G1189, G1194, and G1195 of ES7L-E, which tightly surround SBP2 on the $80 \mathrm{~S}$ ribosome. Similar protection from hydroxyl radicals was observed in the 60S $\cdot \mathrm{CTSBP} 2$ complex, supporting this finding. Base-specific probing in the 60S $\cdot$ CTSBP2 complex revealed enhanced accessibilities of the ES7L-E nucleotides C1180 and C1181 to DMS, and G1185 to kethoxal. Such a reactivity would imply that SBP2 induces structural rearrangements at the apex of ES7L-E upon binding. Interestingly, G1185 is conserved in the 12 organisms analyzed as the partner of the conserved C1176-G1185 base pair, and could therefore play an important as yet unknown role. However, the kethoxal reactivity of G1185 must be taken with care because G1185 is not single stranded, and kethoxal can occasionally generate base-pair disruption. In H89, A4414 and A4422 showed enhanced accessibility to DMS. Altogether the findings in this report, extending our previous ones (Kossinova et al. 2013), constitute the first evidence that the $28 \mathrm{~S}$ rRNA plays a key role in the binding of SBP 2 to the ribosome by implicating nucleotides in helix ES7L-E. As we can judge from the cryo-EM structure of the human ribosome (Anger et al. 2013), ES7L-E 
A

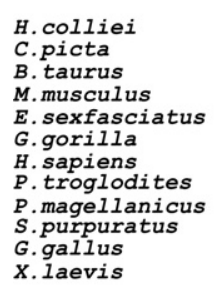

B

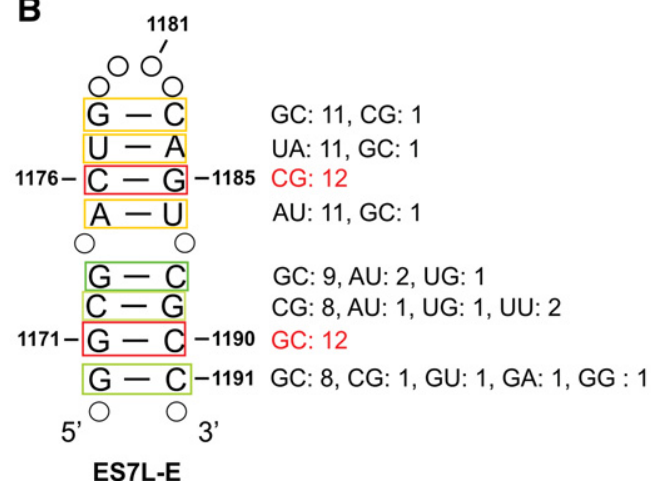

ES7L-E
ES7L-E

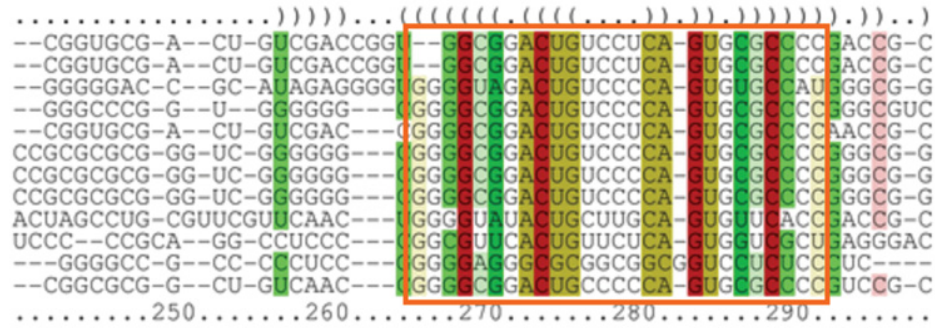

$\ldots \ldots \ldots 250 \ldots \ldots 260 \ldots \ldots 270 \ldots \ldots 280 \ldots \ldots 29 . \ldots \ldots$

FIGURE 6. Structure-based alignment of expansion segment ES7L-E sequences in $28 \mathrm{~S}$ rRNAs arising from 12 vertebrates and invertebrates. ( $A$ ) The region boxed shows 2D structure conservation through base covariations of a section of helix ES7L-E. Color code: The hues show sequence conservation (red corresponds to absolutely conserved and green indicates the least conserved base pairs) and saturation decreases with the number of compatible base pairs, thus showing structural conservation (generated automatically by LocARNA). Parentheses indicate base pairs. Because most of the sequences are partial, numbering according to the human sequence was not possible. The first nucleotide in the sequence of Homo sapiens corresponds to C1148. (B) Secondary structure model of a section of the human ES7L-E helix supported by the base covariations shown in A. The number of covariations for each base pair is indicated on the right. Color code as in $A$ and numbering as in Figure 5A. Open circles represent nonconserved nucleotides in the apical loop and base pairs that do not covary.

is moderately involved in the contact with other ribosomal components. In particular, only three nucleotides (of the 13 ones we have found protected by SBP2 against hydroxyl radicals) are located in close proximity to the amino acid side chains of ribosomal protein L5e.

Helix ES7L-E is part of the large expansion segment ES7L (866 nt) of the human 28S rRNA. We showed that a portion of the 2D structure of helix ES7L-E is conserved among vertebrate and several invertebrate species (at least in echino- derms and mollusks). SBP2 amino acids 527-540 in the Krich domain important for SBP2-ribosome interactions are conserved in vertebrates as well (Takeuchi et al. 2009). Remarkably, the $28 \mathrm{~S}$ rRNAs of land plants that do not synthesize selenoproteins have no ES7L-E at all (Cannone et al. 2002). The above and our findings suggest that during selenocysteine insertion, the conserved K-rich motif of SBP2 interacts with the conserved ES7L-E helix. This suggestion is also supported by the observations of Gupta et al. (2013)
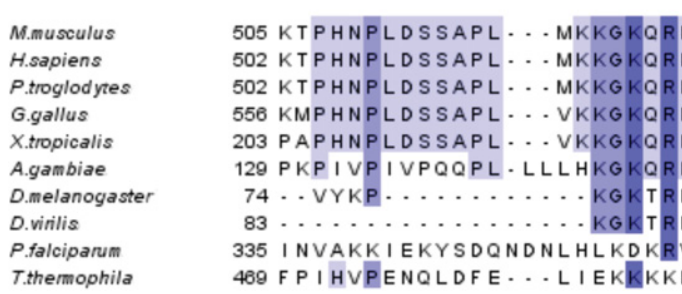

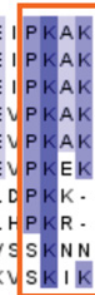

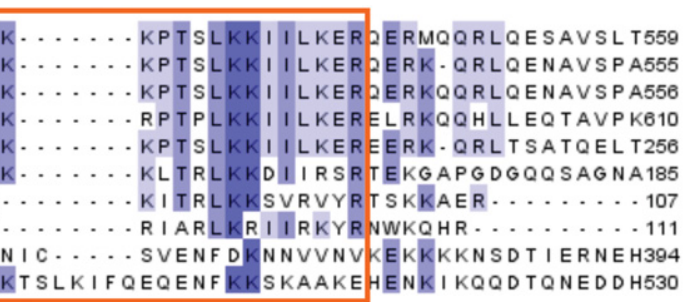

K-rich domain

FIGURE 7. Multiple sequence alignment of the SBP2 K-rich domain. The K-rich domain, corresponding to residues 517-544 in the human SBP2, is boxed. SBP2 sequences are from H. sapiens (UniprotKB accession number Q96T21), Pan troglodytes (H2QXFS), Mus musculus (Q3U1C4), Gallus gallus (XP_424425.4), Xenopus tropicalis (NP_001090731.1), A. gambiae (Donovan and Copeland 2009), D. melanogaster (NP_648204.1), Drosophila virilis (XP_002046871.1), P. falciparum (XP_001351170.1), and T. thermophila (XP_001011959) and were aligned by MUSCLE (Edgar 2004) and displayed with JalView. 
showing that ribosomes from non-Sec-utilizing organisms are unable to support Sec incorporation. As a matter of fact, to carry out selenoprotein synthesis in wheat-germ extract (that is unable to support selenoprotein synthesis), these investigators had to complement it not only with specialized factors and $\mathrm{tRNA}^{\mathrm{Sec}}$ but also with mammalian ribosomes. One can see from the available 28S rRNA 2D structures (Cannone et al. 2002) that ES7L-E differs or is absent in selenoprotein-making organisms of algaea, protists, and most invertebrates. Interestingly, the findings described in this work establish that sequence/structure changes in ES7L-E are accompanied by amino acid changes in the K-rich region of SBP2, very likely for maintaining the ability of the protein to interact with the $60 \mathrm{~S}$ subunit. In other words, a correlation exists between the structure of ES7L-E and the SBP2 amino acid composition in the K-rich region. The lack of correlation between Drosophila SBP2 and mammalian ribosomes could explain why this protein, which carries different amino acids from mammals in the K-rich region, displayed a drastically lower selenoprotein synthesis activity in rabbit reticulocyte lysate compared with human SBP2 (Takeuchi et al. 2009). This minor activity of dSBP2 could have related to its eukaryote-specific L7Ae domain, whose mammalian homolog was shown to be able to weakly bind to the ribosome (Donovan et al. 2008). Our data, combined with those of the literature cited above, strongly suggest that in vertebrates and a few invertebrates the K-rich domain of SBP2 interacts with helix ES7L-E of the 28S rRNA. Concerning lower eukaryotes, we can hypothesize that the lack of helix ES7L-E in the $28 \mathrm{~S}$ rRNA is compensated by changes in the amino acids of the SBP2 K-rich domain in order to provide SBP2 binding to the shortened ES7L.

According to the cryo-EM model of the human 80 S ribosome (Anger et al. 2013), ES7L-E resides in the 80 S ribosome on the solvent side of the $60 \mathrm{~S}$ subunit, near the ribosomal A site (Fig. 8A). Such a location for the SBP2-binding site would be in good accordance with the function of SBP2 proposed by Gonzalez-Flores et al. (2012), which is to facilitate delivery of the eEFSec $\cdot$ Sec-tRNA ${ }^{\mathrm{Sec}}$. GTP ternary complex to the ribosomal A site. Helix H89 of the 28S rRNA resides in the $80 \mathrm{~S}$ ribosome at the $60 \mathrm{~S}$ subunit surface, facing the $40 \mathrm{~S}$ subunit and extending from the peptidyl transferase center (PTC) loop (Anger et al. 2013). The secondary structure of helix H89 is extremely well conserved in the three domains of life (Cannone et al. 2002). Its apical loop is involved in the binding of IF2 in bacteria (La Teana et al. 2001) and eIF5B in eukaryotes (Unbehaun et al. 2007); the helix itself is essential for maintaining translation fidelity in bacteria (O'Connor and Dahlberg 1995) and its structure is important for ribosome peptidyl transferase function in E. coli (Burakovsky et al. 2011). Moreover H89, together with helices H90H92, forms the aminoacyl-tRNA accommodation corridor (Sanbonmatsu et al. 2005). Thus, H89 is involved in the different steps of the translation process. During Sec insertion, the conformational changes implicating $\mathrm{H} 89$, namely the in-

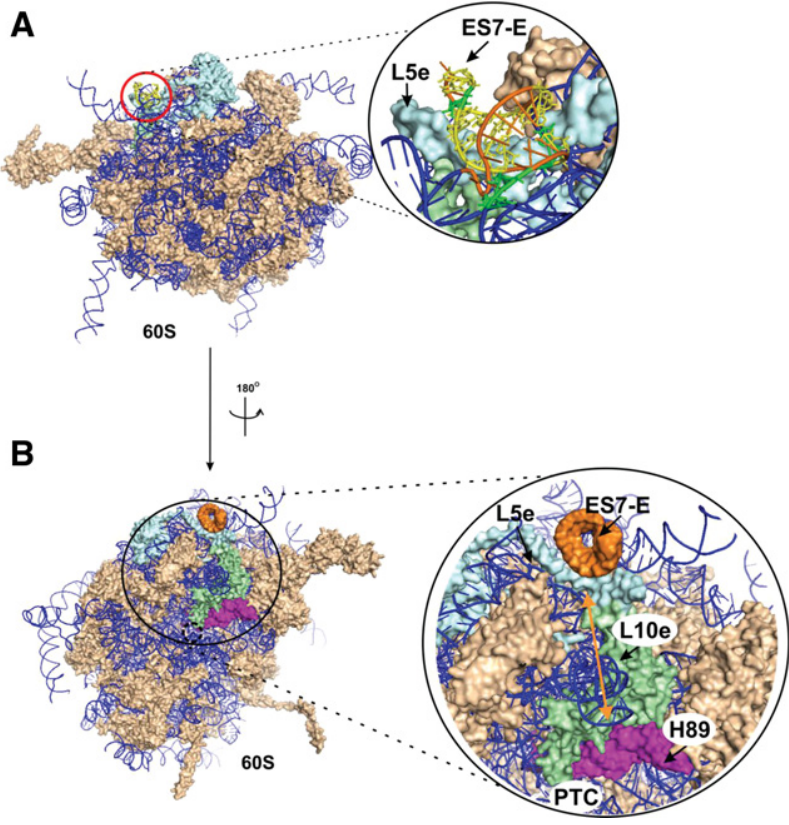

FIGURE 8. Mapping the SBP2 location on the cryo-EM structure of human 80 S ribosomes. (A) Location of ES7L-E in the 80 S ribosome. The red circle designates the putative SBP2 site. The structure of the SBP2binding site is presented in the blowup. The structure of the human $60 \mathrm{~S}$ subunit (solvent sideview) extracted from the $80 \mathrm{~S}$ ribosome structure (Anger et al. 2013) is presented (PDB accession numbers 3J3B, 3J3F). Ribosomal proteins are shown in light brown, rRNAs are displayed as a blue ribbon. (In the blowup) ES7L-E is shown in orange, nucleotides whose ribose moieties were protected by CTSBP2 from hydroxyl radical cleavages are shown in yellow, nucleotides cross-linked to SBP2 are shown in green. $(B)$ The hypothetical pathway of the SBP2-induced conformational changes in the ribosome. The 60 S subunit (Anger et al. 2013) is shown from the intersubunit side. Ribosomal proteins and rRNAs are presented in light brown and blue, respectively. The $60 \mathrm{~S}$ subunit region where the conformational transition occurs is zoomed: ES7L-E, orange; H89, magenta; RPL5e, light blue; RPL10e, light green. The location of the PTC is indicated. The arrow points to the distance between ES7L-E and H89 helices that is $\sim 85 \AA$ (see text).

creased reactivity to DMS of A4414 and A4422 (this study) and of the 2'OH ribose of U4419 and C4421 to benzoyl cyanide (Caban and Copeland 2012), could be a consequence of the structural transitions in the $60 \mathrm{~S}$ subunits caused by the contacts of SBP2 with ES7L-E inducing conformational changes in this helix at C1180, C1181, and G1185. In this respect, we found that at least $85 \AA$ separate ES7L-E from H89 (measured with PyMol) (DeLano 2002) in the cryo-EM model of the human 80 S ribosome (Anger et al. 2013). To explain how SBP2 could induce conformational changes in H89 at a distance, we propose the following hypothesis. As ES7L-E is in close proximity to ribosomal protein L5e, which in turn contacts L10e, and as the N-terminal "hook" of L10e inserts into the H89 bulge (Anger et al. 2013), the SBP2-induced conformation changes at the apex of helix ES7L-E could propagate to H89 (Fig. 8B). Remarkably, the yeast L10e has been already considered as the protein playing a key role in the allosteric transmission of information by 
conformational rearrangements through the ribosome (Petrov et al. 2008; Sulima et al. 2013). Gonzalez-Flores et al. (2012) propose that the conformational changes in $\mathrm{H} 89$ provide the ability of $\mathrm{H} 89$ to interact with Domain IV of the elongation factor eEFSec in order to dissociate the ternary complex eEFSec $\cdot$ Sec-tRNA ${ }^{\mathrm{Sec}} \cdot \mathrm{GTP}$ and to deliver the Sec-tRNA ${ }^{\text {Sec }}$ to the A site.

The results of our study shed light on structural aspects of the SBP2-ribosome interactions in the course of selenoprotein synthesis. We have shown for the first time that the $28 \mathrm{~S}$ rRNA is involved in SBP2 binding and identified ES7L$\mathrm{E}$ as the helix contacting SBP2. This helix is moderately involved in intraribosomal interactions and its 2D structure is highly conserved in vertebrates and a few invertebrates by virtue of a number of base covariations. We have also determined the bases of the $28 \mathrm{~S}$ rRNA involved in the conformational changes induced by SBP2 binding to the ribosome. Additionally, the findings presented herein led us to propose the localization of the SBP2 binding site on the human 80 S ribosome.

\section{MATERIALS AND METHODS}

\section{Preparation of recombinant CTSBP2}

CTSBP2 (amino acids 343-854) fused to a 6xHis N-terminal tag was expressed in E. coli BL21(DE3)RIL strand (Novagene) as described in Takeuchi et al. (2009).

\section{Purification of human ribosomal subunits}

Human ribosomal $40 \mathrm{~S}$ and $60 \mathrm{~S}$ subunits were isolated from fullterm placenta as described in Matasova et al. (1991). The concentration of subunits was determined assuming that one $\mathrm{A}_{260}$-unit equals $50 \mathrm{pmol}$ and $25 \mathrm{pmol}$ in the case of $40 \mathrm{~S}$ subunits and $60 \mathrm{~S}$ subunits, respectively (Matasova et al. 1991). The activities of purified ribosomes were validated by poly-U-dependent synthesis of ${ }^{14} \mathrm{C}$-polyphenylalanine in vitro.

\section{Formation of CTSBP2 $\bullet$ ribosome complex}

The $0.5 \mu \mathrm{M}$ 60S subunits were incubated with $1.5 \mu \mathrm{M}$ CTSBP2 in 50 $\mu \mathrm{L}$ of buffer A (20 mM HEPES-KOH at pH 7.5, $100 \mathrm{mM} \mathrm{KCl,} 2 \mathrm{mM}$ $\mathrm{MgCl}_{2}, 1 \mathrm{mM} \mathrm{DTT}$ ) at $25^{\circ} \mathrm{C}$ for $30 \mathrm{~min}$. The complex was isolated by centrifugation in 10\%-30\% sucrose gradient in buffer A (rotor SW41 [Beckman Coulter], 23,000 rpm, $17 \mathrm{~h}, 4^{\circ} \mathrm{C}$ ). Proteins in fractions containing ribosomal subunits were TCA precipitated. Pellets were dissolved and analyzed on 12\% SDS-PAGE. After electrophoresis, the gel was stained with Coomassie BB R250 and analyzed using QuantityOne software.

\section{Diepoxybutane cross-linking}

CTSBP2-ribosome complexes were formed in $50 \mu \mathrm{L}$ of buffer A as described above. Cross-linking was initiated by addition of $0.5 \%$ $(\mathrm{v} / \mathrm{v})$ diepoxybutane. The mixture was incubated for $45 \mathrm{~min}$ at $37^{\circ} \mathrm{C}$.
The cross-linking reaction was quenched by addition of $50 \mathrm{mM}$ Tris- $\mathrm{HCl}$ ( $\mathrm{pH}$ 7.5). After cross-link formation, excess of uncrosslinked CTSBP2 was removed by centrifugation in 10\%-30\% sucrose gradient in buffer A containing $450 \mathrm{mM} \mathrm{KCl}$ (rotor SW41, 23,000 rpm, $17 \mathrm{~h}, 4^{\circ} \mathrm{C}$ ). Fractions corresponding to $60 \mathrm{~S}$ and $40 \mathrm{~S}$ subunits were ethanol precipitated, dissolved in buffer A, blotted onto nitrocellulose membrane, and analyzed for CTSBP2 content with rabbit polyclonal anti-SBP2 antibodies, which were shown beforehand not to cross-react with ribosomal proteins (1/2500 dilution). Membranes were then treated with anti-rabbit HRP-conjugated secondary antibody (1/10000 dilution), revealed with the ECL-plus kit (GE Healthcare) and exposed to either Xray film (GE Healthcare) or ChemiDoc XRS (BioRad). To analyze the cross-link distribution between rRNAs and proteins in $60 \mathrm{~S}$ subunits, the corresponding subunit fraction prepared as described above was divided into two halves. One half was used for protein extraction with acetic acid according to Hardy et al. (1969), and total rRNA was isolated from another half by phenol extraction as in Graifer et al. (1994). Both ribosomal protein and total rRNA fractions were analyzed with anti-SBP2 antibody as described above. To analyze cross-link distribution between rRNAs in the 60S subunit, the corresponding subunit fraction prepared as described above was incubated for $30 \mathrm{~min}$ at $37^{\circ} \mathrm{C}$ in $0.5 \%$ SDS, $5 \mathrm{mM} \mathrm{NaOH}$-EDTA ( $\mathrm{pH} 7.5$ ). The mixture was layered onto a $5 \%-20 \%$ sucrose gradient in $20 \mathrm{mM}$ Tris- $\mathrm{HCl}$ ( $\mathrm{pH}$ 7.5), 2 mM EDTA, 0.1\% SDS, and centrifuged for $17 \mathrm{~h}$ at 27,000 rpm (rotor SW41). After centrifugation, fractions were ethanol precipitated, the pellets dissolved in a minimal amount of water, and blotted onto a nitrocellulose membrane. The SBP2 signal was detected as above.

Alternatively after quenching, the mixture was supplemented with $0.1 \%$ SDS, $4 \mathrm{mM}$ EDTA, $0.05 \mathrm{mg} / \mathrm{mL}$ proteinase $\mathrm{K}$, and incubated for $20 \mathrm{~min}$ at $37^{\circ} \mathrm{C}$. rRNA was isolated by phenol extraction. Reverse transcription and product analysis were carried out as described in Malygin et al. (2013).

\section{2-iminothiolane cross-linking}

CTSBP2-ribosome complexes were formed as described above. CTSBP2-rRNA cross-links and SBP2-ribosomal proteins cross-links with 2-iminothiolane were performed as described (Kenny et al. 1979; Brimacombe et al. 1988). CTSBP2-rRNA cross-links and CTSBP2-ribosomal proteins cross-links were analyzed as described above.

\section{Hydroxyl radical, kethoxal, and DMS reactions}

Hydroxyl radical cleavage of $28 \mathrm{~S}$ rRNA in $60 \mathrm{~S}$ or $80 \mathrm{~S}$ ribosomes $(0.5$ $\mu \mathrm{M})$ and their complexes with CTSBP2 (1.5 $\mu \mathrm{M}$ CTSBP2) was performed as described in Malygin et al. (2013). Kethoxal and dimethylsulfate (DMS) modifications were performed according to $\mathrm{Xu}$ and Culver (2009) with the only modification that the final DMS concentration was $0.15 \%(\mathrm{v} / \mathrm{v})$. The RNA was isolated by phenol extraction. For reverse transcription, $5^{\prime}-{ }^{32} \mathrm{P}$-labeled primers complementary to the human $28 \mathrm{~S}$ rRNA sequence regions 196-212, 394413, 508-525, 693-709, 735-753, 948-968, 1178-1195, 1221-1240, 1298-1315, 1435-1454, 1589-1605, 1792-1809, 1991-2008, 21602178, 2313-2331, 2406-2422, 2618-2639, 2795-2811, 2889-2907, 3047-3064, 3260-3277, 3626-3644, 3809-3829, 4036-4055, 41844200, 4361-4378, 4495-4515, 4540-4558, 4721-4739, 4880-4898, 
and 5010-5028 were used. Reverse transcription and product analysis were carried out as described in Malygin et al. (2013).

\section{Structure-based sequence alignment of ES7L}

rRNA sequences corresponding to ES7L helices C-H (nt 956-1280 of the human 28S rRNA; numbering according to Anger et al. 2013) were aligned with the web-based tool LocARNA (Will et al. 2007) using the global alignment method in LocARNA-P mode. GenBank accession numbers: H. sapiens NR_003287, Bos taurus NR_036644, Chrysemys picta AY859626, Epiplatys sexfasciatus FJ872049, Xenopus laevis x02995, G. gallus DQ018756, Gorilla gorilla M30951.1, Strongylocentrotus purpuratus AF212171, P. troglodytes M30950.1, Hydrolagus colliei AF061799, M. musculus X00525.1, and Placopecten magellanicus AF342798.1.

\section{SUPPLEMENTAL MATERIAL}

Supplemental material is available for this article and can also be accessed in PDF format at http://www.niboch.nsc.ru/lib/exe/fetch. php/ru/structure/labs/kar/2014_sd_kossinova_et_al.pdf.

\section{ACKNOWLEDGMENTS}

We thank C. Allmang (IBMC CNRS, Strasbourg, France) for the gift of materials and helpful discussions and Prof. E. Westhof (IBMC CNRS, Strasbourg, France) for his input and comments on the manuscript. We are grateful to A. Schweigert and S. Baudrey for technical assistance. O.K. was a cosupervised $\mathrm{PhD}$ student with the Institute of Chemical Biology and Fundamental Medicine, SB RAS, and the Universite de Strasbourg, partly supported by the French government. This work was supported by the ARCUS and Supramolecular Chemistry programs (to G.K. and A.K.), the CNRS Laboratoire International Associé LIA NUCPROT (to A.K.), and the Russian Foundation for Basic Research (grant 1204-93111-CNRSL_a to G.K.).

Received February 20, 2014; accepted March 27, 2014.

\section{REFERENCES}

Allmang C, Carbon P, Krol A. 2002. The SBP2 and 15.5 kD/Snu13p proteins share the same RNA binding domain: identification of the SBP2 amino acids important for the SECIS binding. RNA 8: $1308-1318$.

Anger A, Armache JP, Berninghausen O, Habeck M, Subklewe M, Wilson D, Beckman R. 2013. Structures of the human and Drosophila 80S ribosome. Nature 497: 80-85.

Baumert H, Skold SE, Kurland C. 1978. RNA-protein neighbourhoods of the ribosome obtained by cross-linking. Eur J Biochem 89: 353-359.

Berry MJ, Banu L, Chen Y, Mandel S, Kieffer J, Harney J, Larsen P. 1991. Recognition of UGA as a selenocysteine codon in type I deiodinase requires sequences in the $3^{\prime}$ untranslated region. Nature 353: 273-276.

Brimacombe R, Stiege W, Kyriatsoulis A, Maly P. 1988. Intra-RNA and RNA-protein cross-linking techniques in Escherichia coli ribosomes. Methods Enzymol 164: 287-309.

Bubenik JL, Driscoll DM. 2007. Altered RNA binding activity underlies abnormal thyroid hormone metabolism linked to a mutation in sele- nocysteine insertion sequence-binding protein 2. J Biol Chem 282: 34653-34662.

Burakovsky D, Sergiev P, Steblyanko M, Konevega A, Bogdanov A, Dontsova O. 2011. The structure of helix 89 of $23 \mathrm{~S}$ rRNA is important for peptidyl transferase function of Escherichia coli ribosome. FEBS Lett 585: 3073-3078.

Caban K, Copeland PR. 2012. SECIS binding protein 2 alters the conformational dynamics of residues involved in tRNA accommodation in 80S ribosomes. J Biol Chem 287: 10664-10673.

Caban K, Kinzy SA, Copeland PR. 2007. The L7Ae RNA binding motif is a multifunctional domain required for the ribosome-dependent Sec incorporation activity of Sec insertion sequence binding protein 2 . Mol Cell Biol 27: 6350-6360.

Cannone J, Subramanian S, Schnare M, Collett J, D'Souza L, Du Y, Feng B, Lin N, Madabusi LV, Muller K, et al. 2002. The comparative RNA web (CRW) site: an online database of comparative sequence and structure information for ribosomal, intron, and other RNAs. BMC Bioinformatics 3: 2. [Correction: BMC Bioinformatics 3: 15.]

Cléry A, Bourguignon-Igel V, Allmang C, Krol A, Branlant C. 2007. An improved definition of the RNA-binding specificity of SECISbinding protein 2 , an essential component of the selenocysteine incorporation machinery. Nucleic Acids Res 35: 1868-1884.

Copeland PR, Fletcher JE, Carlson BA, Hatfield DL, Driscoll DM. 2000. A novel RNA binding protein, SBP2, is required for the translation of mammalian selenoprotein mRNAs. EMBO J 19: 306-314.

Copeland PR, Stepanik VA, Driscoll DM. 2001. Insight into mammalian selenocysteine insertion: domain structure and ribosome binding properties of Sec insertion sequence binding protein 2. Mol Cell Biol 21: 1491-1498.

DeLano WL. 2002. The PyMOL Molecular Graphics System. DeLano Scientific, San Carlos, CA.

Donovan J, Copeland P. 2009. Evolutionary history of selenocysteine incorporation from the perspective of SECIS binding proteins. BMC Evol Biol 9: 229-247.

Donovan J, Caban K, Ranaweera R, Gonzalez-Flores J, Copeland P. 2008. A novel protein domain induces high affinity selenocysteine insertion sequence binding and elongation factor recruitment. $J$ Biol Chem, 283: 35129-35139.

Edgar R. 2004. MUSCLE: multiple sequence alignment with high accuracy and high throughput. Nucleic Acids Res 32: 1792-1797.

Fagegaltier D, Hubert N, Yamada K, Mizutani T, Carbon P, Krol A. 2000. Characterization of $\mathrm{mSelB}$, a novel mammalian elongation factor for selenoprotein translation. EMBO J 19: 4796-4805.

Fletcher J, Copeland P, Driscoll D, Krol A. 2001. The selenocysteine incorporation machinery: interactions between the SECIS RNA and the SECIS-binding protein SBP2. RNA 7: 1442-1453.

Gonzalez-Flores JN, Gupta N, DeMong LW, Copeland PR. 2012. The selenocysteine-specific elongation factor contains a novel and multi-functional domain. J Biol Chem 287: 38936-38945.

Graifer D, Juzumiene D, Karpova G, Wollenzein P. 1994. mRNA binding track in the human $80 \mathrm{~S}$ ribosome for mRNA analogues randomly substituted with 4-thiouridine residues. Biochemistry 33: 6201-6206.

Gupta N, DeMong L, Banda S, Copeland P. 2013. Reconstitution of selenocysteine incorporation reveals intrinsic regulation by SECIS elements. J Mol Biol 425: 2415-2422.

Hardy S, Kurland C, Voynow P, Mora G. 1969. The ribosomal proteins of Escherichia coli. I. Purification of $30 \mathrm{~S}$ ribosomal proteins. Biochemistry 8: 2897-2905.

Kenny J, Lambert J, Traut R. 1979. Cross-linking of ribosomes using 2iminothiolane and identification of cross-linked proteins by diagonal polyacrylamide/SDS gel electrophoresis. Methods Enzymol 59: 534-560.

Klinge S, Voigts-Hoffman F, Leibendgut M, Arpagus S, Ban N. 2011. Crystal structure of the eukaryotic $60 \mathrm{~S}$ ribosomal subunit in complex with initiation factor 6. Science 334: 941-948.

Koskinen M, Plna K. 2000. Specific DNA adducts induced by some mono-substituted epoxides in vitro and in vivo. Chem Biol Interact 129: 209-229. 


\section{Kossinova et al.}

Kossinova O, Malygin A, Krol A, Karpova G. 2013. A novel insight into the mammalian selenoprotein synthesis. RNA 19: 1147-1158.

La Teana A, Gualerzi CO, Dahlberg A. 2001. Initiation factor IF 2 binds to the $\alpha$-sarcin loop and helix 89 of Escherichia coli $23 \mathrm{~S}$ ribosomal RNA. RNA 7: 1173-1179.

Lescure A, Allmang C, Yamada K, Carbon P, Krol A. 2002. cDNA cloning, expression pattern and RNA binding analysis of human selenocysteine insertion sequence (SECIS) binding protein 2. Gene 291: 279-285.

Malygin A, Kossinova O, Shatsky I, Karpova G. 2013. HCV IRES interacts with the $18 \mathrm{~S}$ rRNA to activate the $40 \mathrm{~S}$ ribosome for subsequent steps of translation initiation. Nucleic Acids Res 41: 87068714.

Matasova N, Myltseva S, Zenkova M, Graifer D, Vladimirov S, Karpova G. 1991. Isolation of ribosomal subunits containing intact rRNA from human placenta: estimation of functional activity of $80 \mathrm{~S}$ ribosomes. Anal Biochem 198: 219-223.

O'Connor M, Dahlberg A. 1995. The involvement of two distinct regions of $23 \mathrm{~S}$ ribosomal RNA in tRNA selection. J Mol Biol 254: 838-847.

Petrov AN, Meskauskas A, Roshwalb SC, Dinman JD. 2008. Yeast ribosomal protein L10 helps coordinate tRNA movement through the large subunit. Nucleic Acids Res 36: 6187-6198.

Sanbonmatsu KY, Joseph S, Tung CS. 2005. Simulating movement of tRNA into the ribosome during decoding. Proc Natl Acad Sci 102: 15854-15859.
Sulima SO, Gulay SP, Anjos M, Patchett S, Meskauskas A, Johnson AW, Dinman JD. 2013. Eukaryotic rpL10 drives ribosomal rotation. Nucleic Acids Res 42: 2049-2063.

Takeuchi A, Schmitt D, Chapple C, Babaylova E, Karpova G, Guigo R, Krol A, Allmang C. 2009. A short motif in Drosophila SECIS Binding Protein 2 provides differential binding affinity to SECIS RNA hairpins. Nucleic Acids Res 37: 2126-2141.

Traut R, Bollen A, Sun T, Hershey J, Sundberg J, Pierce L. 1973. Methyl 4-mercaptobutyrimidate as a cleavable cross-linking reagent and its application to the Escherichia coli 30 S ribosome. Biochemistry 12: 3266-3273.

Tujebajeva RM, Copeland PR, Xu XM, Carlson BA, Harney JW, Driscoll DM, Hatfield DL, Berry MJ. 2000. Decoding apparatus for eukaryotic selenocysteine insertion. EMBO Rep 1: 158-163.

Unbehaun A, Marintchev A, Lomakin I, Didenko T, Wagner G, Hellen C, Pestova T. 2007. Position of eukaryotic initiation factor eIF5B on the $80 \mathrm{~S}$ ribosome mapped by directed hydroxyl radical probing. EMBO J 26: 3109-3123.

Will S, Reiche K, Hofacjer I, Stadlet P, Backofen R. 2007. Inferring noncoding RNA families and classes by means of genome-scale structure-based clustering. PLOS Comput Biol 3: e65.

Wu J, Kozarich J, Stubbe J. 1983. The mechanism of free base formation from DNA by bleomycin. A proposal based on site specific tritium release from Poly(dA·dU). J Biol Chem 258: 4694-4697.

$\mathrm{Xu} \mathrm{Z}$, Culver G. 2009. Chemical probing of RNA and RNA/protein complexes. Methods Enzymol 468: 147-165. 

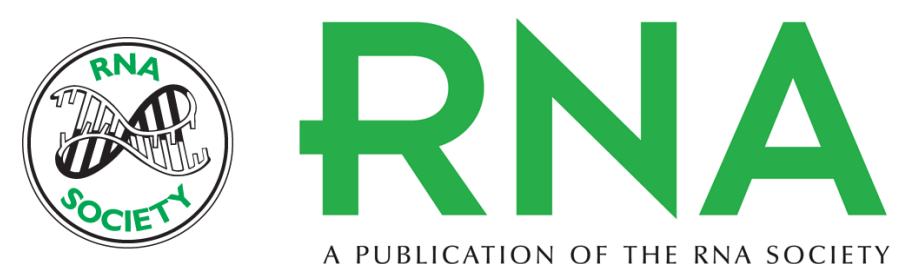

A PUBLICATION OF THE RNA SOCIETY

\section{The SBP2 protein central to selenoprotein synthesis contacts the human ribosome at expansion segment $7 \mathrm{~L}$ of the $28 \mathrm{~S}$ rRNA}

Olga Kossinova, Alexey Malygin, Alain Krol, et al.

RNA 2014 20: 1046-1056 originally published online May 21, 2014

Access the most recent version at doi:10.1261/rna.044917.114

\section{Supplemental http://rnajournal.cshlp.org/content/suppl/2014/04/25/rna.044917.114.DC1 \\ Material}

References This article cites 41 articles, 17 of which can be accessed free at: http://rnajournal.cshlp.org/content/20/7/1046. full.html\#ref-list-1

Creative This article is distributed exclusively by the RNA Society for the first 12 months after the Commons License full-issue publication date (see http://rnajournal.cshlp.org/site/misc/terms.xhtml). After 12 months, it is available under a Creative Commons License (Attribution-NonCommercial 4.0 International), as described at http://creativecommons.org/licenses/by-nc/4.0/.

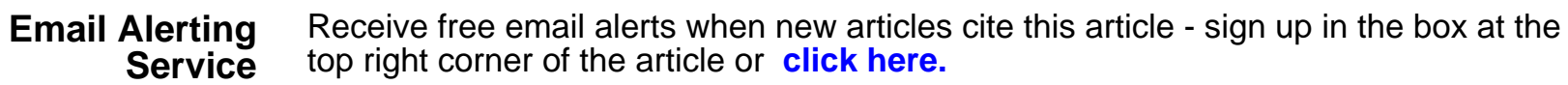

